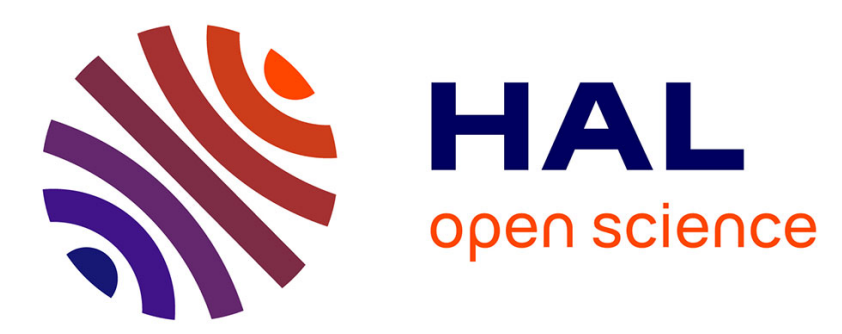

\title{
Supramolecular ladder assemblies as a model for probing electronic interactions between multiple stacked $\pi$-conjugated systems
}

Chih-Huao Huang, Damien Jardel, Guillaume Lautrette, Isabelle Pianet, Alexander Kuhn, Dario M Bassani

\section{To cite this version:}

Chih-Huao Huang, Damien Jardel, Guillaume Lautrette, Isabelle Pianet, Alexander Kuhn, et al.. Supramolecular ladder assemblies as a model for probing electronic interactions between multiple stacked $\pi$-conjugated systems. ChemPhysChem, In press, 10.1002/cphc.202000857 . hal-03042900

\author{
HAL Id: hal-03042900 \\ https://hal.science/hal-03042900
}

Submitted on 7 Dec 2020

HAL is a multi-disciplinary open access archive for the deposit and dissemination of scientific research documents, whether they are published or not. The documents may come from teaching and research institutions in France or abroad, or from public or private research centers.
L'archive ouverte pluridisciplinaire HAL, est destinée au dépôt et à la diffusion de documents scientifiques de niveau recherche, publiés ou non, émanant des établissements d'enseignement et de recherche français ou étrangers, des laboratoires publics ou privés. 


\section{ChemPhysChem}

\section{F Chemistry Europe}

European Chemical Societies Publishing

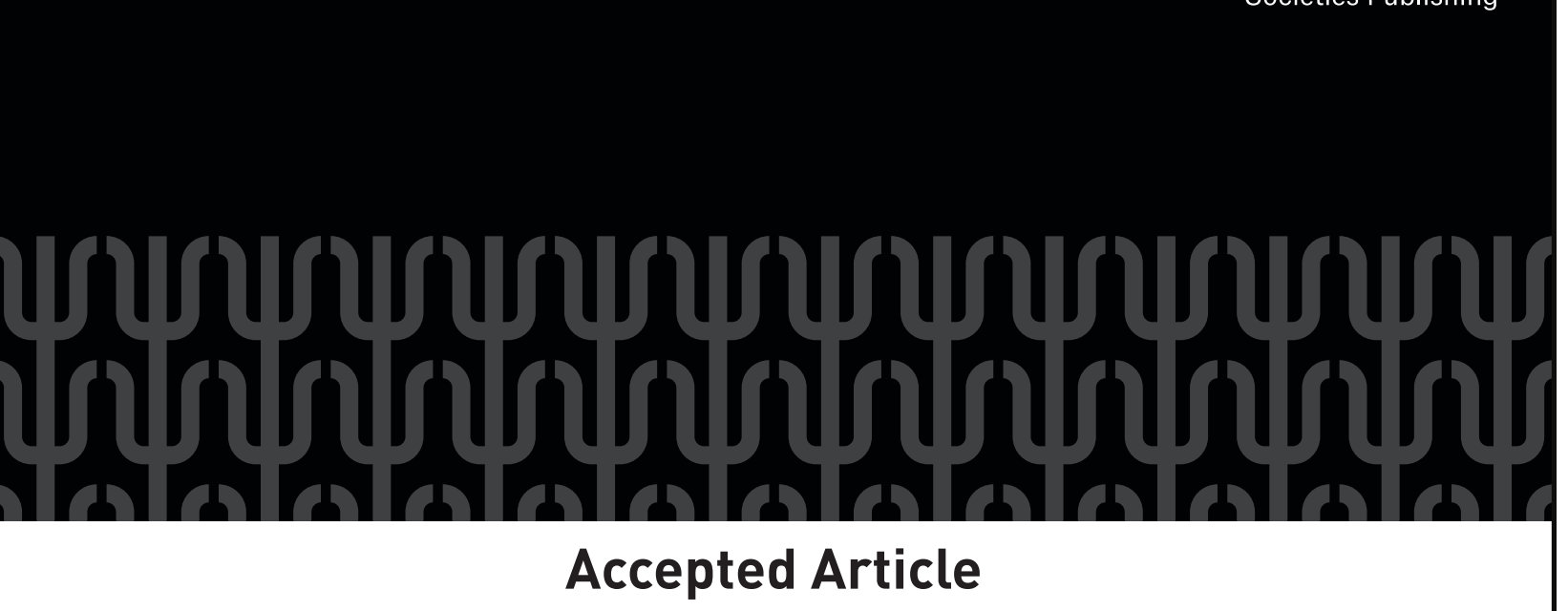

Title: Supramolecular ladder assemblies as a model for probing electronic interactions between multiple stacked m-conjugated systems

Authors: Chih-Huao Huang, Damien Jardel, Guillaume Lautrette, Isabelle Pianet, Alexander Kuhn, and Dario Maria Bassani

This manuscript has been accepted after peer review and appears as an Accepted Article online prior to editing, proofing, and formal publication of the final Version of Record (VoR). This work is currently citable by using the Digital Object Identifier (DOI) given below. The VoR will be published online in Early View as soon as possible and may be different to this Accepted Article as a result of editing. Readers should obtain the VoR from the journal website shown below when it is published to ensure accuracy of information. The authors are responsible for the content of this Accepted Article.

To be cited as: ChemPhysChem 10.1002/cphc.202000857

Link to VoR: https://doi.org/10.1002/cphc.202000857 


\title{
Supramolecular ladder assemblies as a model for probing electronic interactions between multiple stacked $\pi$-conjugated systems
}

\author{
Chi-Huao Huang, ${ }^{[\mathrm{a}]}$ Damien Jardel, ${ }^{[\mathrm{a}]}$ Guillaume Lautrette,${ }^{[\mathrm{a}]}$ Isabelle Pianet, ${ }^{[\mathrm{b}]}$ Alexander Kuhn, ${ }^{[\mathrm{c}]}$ and \\ Dario M. Bassani ${ }^{[\mathrm{a}], *}$
}

Dedicated to the memory of Dr. Olivier Poizat

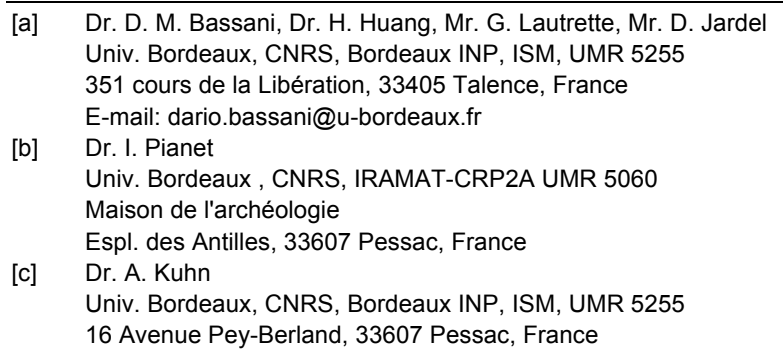

Supporting information for this article is given via a link at the end of the document.

\begin{abstract}
A series of mono-, di-, and tri-topic receptors, in which $\mathrm{H}-$ bonding sites, complementary to those of barbituric acid (BA), are fused, is used to induce the supramolecular assembly of $n \times m$ ladders containing 1,2 , or 3 triphenylenevinylene units appended with BA. The topological constraint enforced by the architectures induces through-space interactions between the electroactive moieties that are reflected in the electronic absorption and emission spectrum. The $n=2, m=2$ or $m=3$ architectures undergo two single electron oxidation events indicative of the formation of the corresponding mono- and di-radical cation species with comproportionation constants of 340 and 70 , respectively. Comparison of the electrochemical potentials suggests that the charges are delocalized over the electroactive units in the assembly.
\end{abstract}

\section{Introduction}

The intrinsic electronic properties of organic materials are mainly defined by the chemical structure of the molecular constituents. However, intermolecular electronic coupling controls the efficiency of long-range exciton and charge carrier diffusion and for this reason through-space interactions play a key role in determining the performance of molecule-based materials for applications in electronics. $\left.{ }^{[1,} 2\right]$ For example, in organic photovoltaic devices, the formation of crystalline polymer domains, in which $\pi$-stacking interactions are large, greatly favor charge separation and transport. ${ }^{[3,4]} \mathrm{A}$ similar situation is found in organic field-effect transistors, where device performance is invariably linked to the charge-carrier mobility of the material, ${ }^{[5,6]}$ and in photosynthetic organisms, where the degree of electronic coupling between chromophores in the antennae is tailored to promote highly efficient energy transfer over long distances. ${ }^{[7-10]}$ For these reasons, investigations of the factors governing the formation of structurally defined aggregates of $\pi$-conjugated materials have been pursued vigorously. ${ }^{[11,12]}$ In particular, controlling the formation of specific supramolecular structures has proven important in adjusting the bulk electronic properties. ${ }^{[13-20]}$ Elegant work from several research groups demonstrated the use of tailored supramolecular interactions to achieve this goal, in particular through the use of organogelating systems in which the $\pi$-conjugated components are welloriented. ${ }^{[1,21-26]}$ In these systems, the chromophores first selfassemble into relatively well-defined architectures that then combine into infinite macroscopic phase-separated structures. ${ }^{[27,}$ 28]

The challenge of obtaining precise molecular data from inhomogeneous systems was largely met in the field of $\pi$ conjugated polymer chemistry by the use of the oligomer approach, in which short, structurally well-defined chains are used to probe the properties of larger and less tractable samples. ${ }^{[29,30]}$ By analogy, a supramolecular approach can be used to direct the formation of finite vs. infinite well-defined supramolecular architectures, in which suitably oriented $\pi-$ conjugated chromophores are maintained in place through noncovalent interactions. ${ }^{[31-33]}$ Supramolecular stacks based on metal ion coordination or hydrogen-bonding $(\mathrm{H}-\mathrm{B})$ have been used to prepare supramolecular analogues of cyclophane-like structures, and these can provide a starting point for the rational design of more extended architectures. ${ }^{[34-39]}$ However, for the purpose of probing the effect of stacking on the electronic properties of the chromophores, H-B interactions provide an advantage over metal ion coordination as they are typically electrochemically silent and do not display electronic absorption bands in the UV-vis region or promote intersystem crossing of nearby excited states.

Herein, we present our results on the use of $\mathrm{H}-\mathrm{B}$ interactions to direct the formation of well-defined supramolecular architectures in which two or three triphenylenevinyle units are maintained in a stacked coplanar geometry. To favor topologies in which the $\pi$-conjugated chromophores are stacked, multiple $\mathrm{H}$-bonding interactions (12 or 18) are used to construct closed 
architectures possessing cooperativity for the introduction of the final component. The topological effects on the electronic properties of the compounds, as probed by using spectroscopic (absorption and emission spectroscopy) and electrochemical (cyclic voltammetry) techniques, show that through-space interactions between the triphenylenevinyle units are present. Formation of the mono- and di-radical cations occurs through two sequential one-electron oxidation steps in which the comproportionation constants depend on the size of the supramolecular assembly.

\section{Results and Discussion}

The supramolecular strategy employed to maintain the desired $\pi$-conjugated chromophores in a fixed topology is based on the construction of supramolecular $(n \times m)$ ladders. Compared to supramolecular racks, the formation of ladders presents the advantage of better controlling the relative orientation and distance between the chromophores and offering a lower entropic contribution towards formation of the final, closed architecture (Figure 1). The connectivity between the different elements is ensured by the formation of $12 \mathrm{H}$-bonds between two barbiturate guests bound to the chromophore and complementary Hamilton-like $\mathrm{H}$-bonding sites ${ }^{[40]}$ on di- and tritopic receptors ( $\mathbf{R} \mathbf{2}$ and $\mathbf{R} 3$, respectively). The strong binding between barbiturates and Hamilton receptors is well documented and favors formation of the host-guest complex even at sub-mM concentrations. ${ }^{[41,42]}$

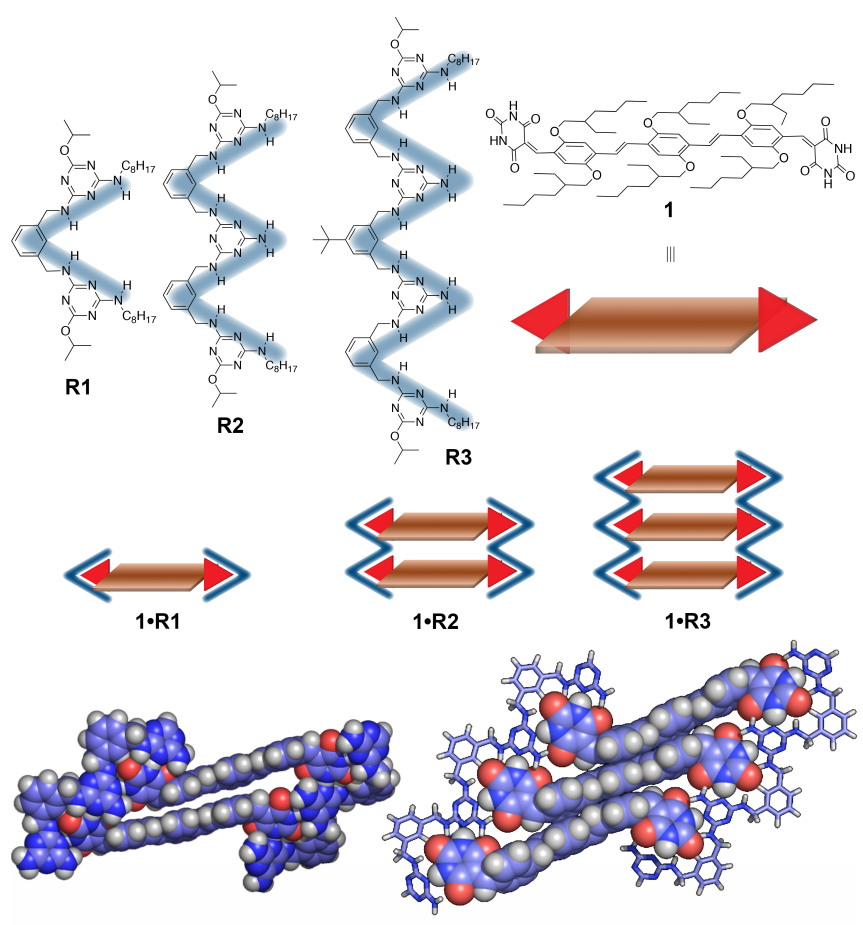

Figure 1. Supramolecular strategy involving the formation of $2 \times 2$ and $2 \times 3$ ladder assembles of triphenylenevinylene $\mathbf{1}$ and receptors $\mathbf{R} 2$ and $\mathbf{R} \mathbf{3}$ via multiple $\mathrm{H}$-bonding interactions. Bottom: Energy-minimized (MM5) molecular structures of $\mathbf{1} \cdot \mathbf{R} \mathbf{2}$ and $\mathbf{1} \cdot \mathbf{R} \mathbf{3}$ (solubilizing chains omitted for simplification).
The synthesis of 1 was achieved through a Knoevenagel condensation between barbituric acid and the corresponding dialdehyde. Although the synthesis of the latter was previously reported via a controlled polycondensation reaction, we found it more expedient to prepare the desired intermediate by the Horner-Wadsworth-Emmons reaction as described by Hummelen and Janssen, ${ }^{[43]}$ followed by Vilsmeier-Haack formylation of the dibromide (Scheme 1). The preparation of the di- and tri-topic receptors makes use of the large difference in reactivity of substituted cyanuric chlorides towards aromatic nucleophilic substitution. ${ }^{[4]}$ This makes it possible to sequentially introduce three different substituents in good yields and high selectivity. Introduction of the last amine residue is achieved using aqueous ammonium hydroxyde at $120^{\circ} \mathrm{C}$ in a sealed vessel. To evidence the effects of $\mathrm{H}$-bonding on the electronic and spectroscopic properties of 1, a reference monotopic receptor (R1) was also prepared.

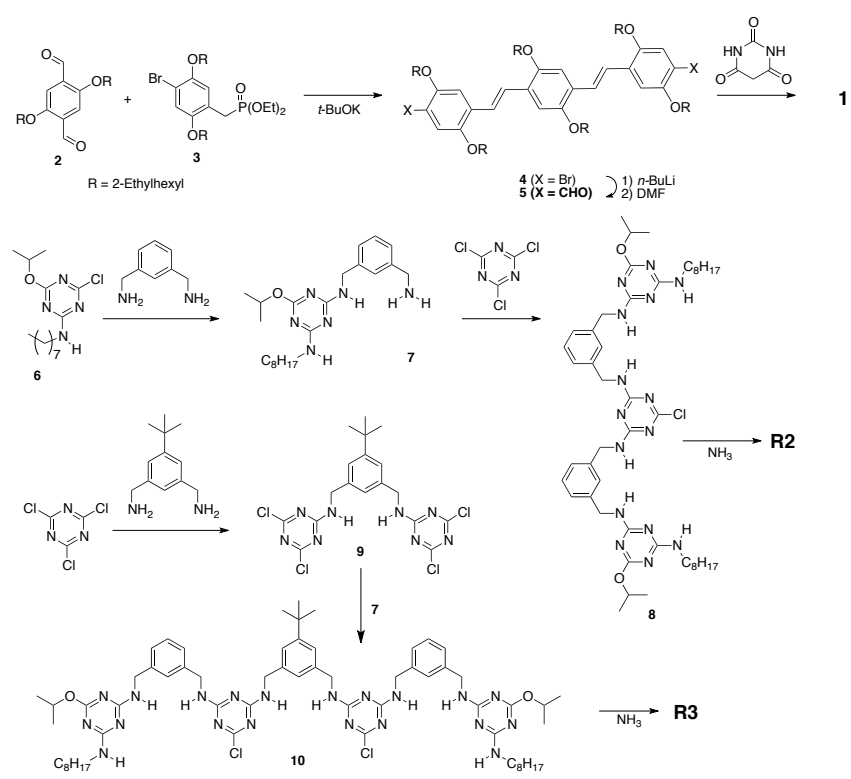

Scheme 1. Synthetic strategy for the preparation of $\mathbf{1}$ and receptors $\mathbf{R} \mathbf{2}$ and R3.

The absorption and emission spectra of $\mathbf{1}$ and the supramolecular assemblies formed in the presence of R1, R2, and $\mathbf{R 3}$ in dichloromethane solutions are shown in Figure 2. It should be noted that $\mathbf{1}$ alone has a tendency towards aggregation even in dilute solutions due to the presence of partially complementary $\mathrm{H}$-bonding sites. The addition of $\mathbf{R} \mathbf{1}$ considerably enhances its solubility by blocking the $\mathrm{H}$-bonding sites. Compared to the absorption of $\mathbf{1} \cdot \mathbf{R} \mathbf{1}$, the absorption of $\mathbf{1}$ alone is shifted hypsochromically by $45 \mathrm{~nm}$ and reduced in intensity, as expected for the formation of $\mathrm{H}$-type aggregates in which the $\pi$-conjugated chromophores are stacked. The situation for $\mathbf{1} \cdot \mathbf{R} \mathbf{2}$ and $\mathbf{1 \cdot R} \mathbf{3}$ is similar, with the absorption spectra of both complexes shifted hypsochromically (by $27 \mathrm{~nm}$ ) with respect to that of $\mathbf{1} \cdot \mathbf{R} \mathbf{1}$. The smaller shift may be a result of the greater distance between the chromophores in the ladder complexes (estimated to be ca. $5 \AA$ ) with respect to that in aggregates of 1 alone. All the species are emissive, indicating that, if formed, the H-aggregation does not possess an ideal, 
stacked geometry in which emission is symmetry-forbidden. In line with the absorption spectra, the emission of all the complexes is hypsochromically shifted with respect to that of $\mathbf{1 \cdot R} \mathbf{1}$, with the greatest shift observed for 1 alone. The nearidentical absorption and emission spectra of $\mathbf{1 \cdot R 2}$ and $\mathbf{1 \cdot R} \mathbf{3}$ suggests that the environment of $\mathbf{1}$ is very similar for both complexes.

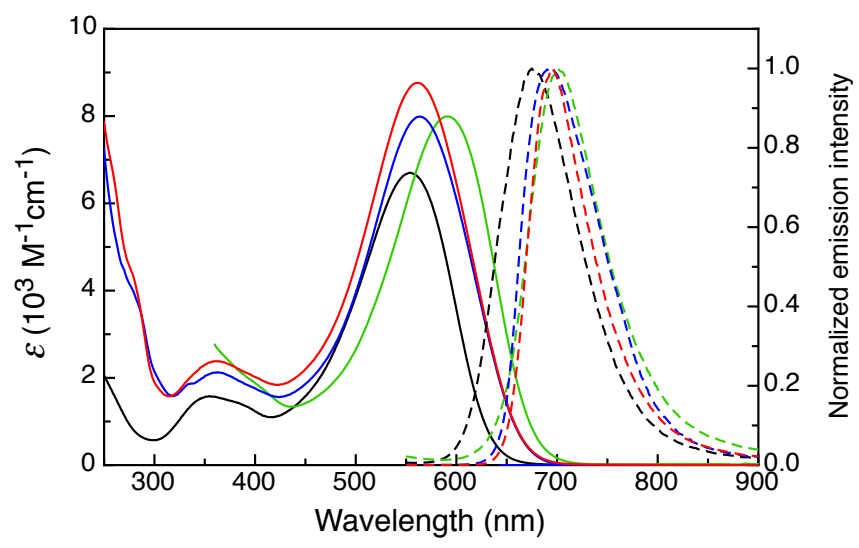

Figure 2. Electronic absorption (solid lines) and normalized emission spectra (dashed lines, $\left.\lambda_{\mathrm{ex}}=500 \mathrm{~nm}\right)$ in dichloromethane of $\mathbf{1}\left(10^{-4} \mathrm{M}\right.$, black), $\mathbf{1} \cdot \mathbf{R} \mathbf{1}\left(10^{-}\right.$ ${ }^{4} \mathrm{M}$, green), $\mathbf{1} \cdot \mathbf{R} \mathbf{2}\left(10^{-4} \mathrm{M}\right.$, blue $)$ and $\mathbf{1} \cdot \mathbf{R} 3\left(1.5 \times 10^{-4} \mathrm{M}\right.$, red $)$.

Evidence for the formation of the $\mathbf{1} \cdot \mathbf{R} \mathbf{2}$ and $\mathbf{1} \cdot \mathbf{R} \mathbf{3}$ complexes was obtained by monitoring the absorption spectra of mixtures of $\mathbf{1}$ and the selected receptor. In particular, Job plots for $\mathbf{1 \cdot R 2}$ clearly show a maximum for a $1: 1$ stoichiometry, in agreement with the formation of a $2: 2$ complex (Fig. 3). The situation for the $\mathbf{1 \cdot R 3}$ complex is somewhat more complex. Although the variations observed in the absorption spectrum are broadly similar to those for $\mathbf{1 \cdot R 2}$, the resultant Job plot is broad over the region between 0.5 and 0.7 . This may be explained by the sequential formation of both the $2: 2$ and $2: 3$ complexes as the relative stoichiometry of the components is varied. Furthermore, unlike for $\mathbf{1 \cdot R 2}$, Job plots determined at different wavelengths give different profiles, as expected for the formation of $>1$ complexes of differing stoichiometry. ${ }^{[45]}$ The formation of the complexes is reasonably fast, as we observe that the ${ }^{1} \mathrm{H}$ NMR signals of the $\mathbf{1} \cdot \mathbf{R} \mathbf{2}$ complex appear rapidly upon mixing and do not change over a 6 -hr period (Figure S5). Variable temperature $1 \mathrm{H}$ NMR shows that this complex is stable up to ca. $320 \mathrm{~K}$ (Figure S6). Additionally, we note that titration of $\mathbf{1}$ with $\mathbf{R 2}$ is accompanied by a 5-ppm downfield shift of the imide $\mathrm{NH}$ of $1(\delta$ 13.8), which is commonly associated with the formation of barbiturate receptor $\mathrm{H}$-bonded assemblies (Figure S7). ${ }^{[0]}$ Further addition of $\mathbf{R} 2$ beyond the expected $2: 2$ stoichiometry results in the appearance of a new resonance at $\delta 13.5$. In the case of the $\mathbf{1} \cdot \mathbf{R} \mathbf{3}$ complex, the assignment of the $\mathrm{NH}$ resonances is complicated by the existence of different sites corresponding to the central and peripheral binding sites. Nonetheless, the observed changes are broadly consistent with that observed for the $\mathbf{1} \cdot \mathbf{R} \mathbf{3}$ complex (Figure S8).

The formation of the proposed $\mathbf{1} \cdot \mathbf{R} \mathbf{2}$ and $\mathbf{1 \cdot R} \mathbf{3}$ architectures is also consistent with their diffusion constants in solution. According to molecular modelling, the $2 \times 2$ and $2 \times 3 \mathbf{1} \cdot \mathbf{R} 2$ and $\mathbf{1} \cdot \mathbf{R} 3$ complexes possess a shape that is relatively spherical due to the 12 or 18 2-ethylhexyloxy solubilizing chains on the periphery. Diffusion-ordered NMR spectroscopy (DOSY $)^{[46]}$ was used to determine the diffusion coefficients of the two complexes and compare them to that of 1 alone (Table 1). In the case of $\mathbf{1} \cdot \mathbf{R 2}$, the diffusion constant is found to be $2 \times 10^{-9} \mathrm{~m}^{2} / \mathrm{s}$, which corresponds to a sphere whose hydrodynamic radius $(1.0 \mathrm{~nm})$ is very close to that calculated for the complex by molecular modelling $(1.1 \mathrm{~nm})$. In agreement with the formation of the expected architecture for $\mathbf{1} \cdot \mathbf{R} 3$, a single major diffusing species was observed whose diffusion constant is smaller than that of $\mathbf{1 \cdot R 2}$, giving a $20 \%$ increase in hydrodynamic radius as expected for the larger assembly. The aggregation of 1 alone in dichloromethane was also probed by DOSY. A diffusing species associated to a hydrodynamic radius of $3.1 \mathrm{~nm}$ was found, which is substantially larger than that for $\mathbf{1} \cdot \mathbf{R} \mathbf{2}$ and $\mathbf{1} \cdot \mathbf{R} \mathbf{3}$. This indicates that the average size of the aggregates of 1 is larger than that of $\mathbf{1} \cdot \mathbf{R} 3$ and that they may contain $5-10$ molecules per aggregate.
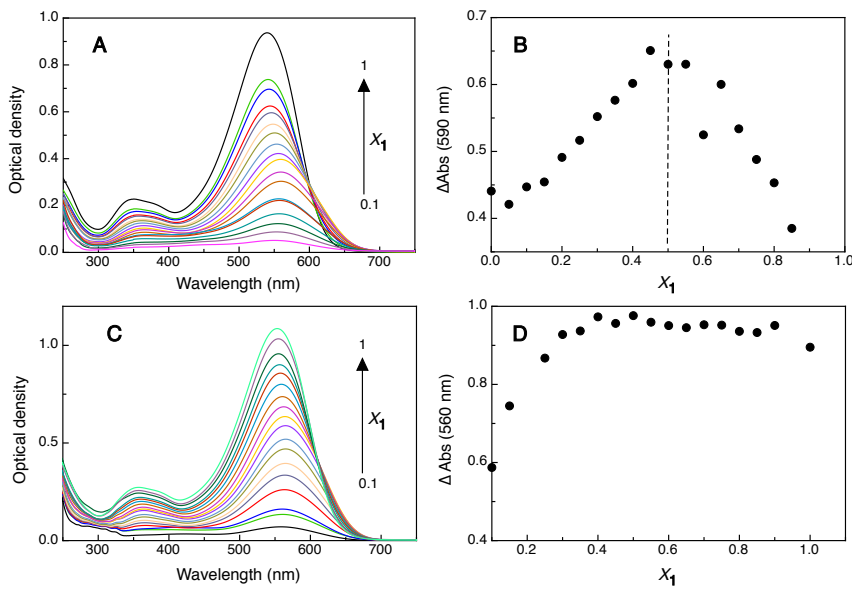

Figure 3. Electronic absorption of $\mathbf{1}$ and $\mathbf{R 2}$ at $10^{-4} \mathrm{M}$ in dichloromethane according to the method of continuous variations $(A)$ and resultant Job plot $(B)$ of $\Delta \mathrm{Abs}$ at $590 \mathrm{~nm}$. Dashed line indicates 1:1 stoichiometry. C: Electronic absorption of $\mathbf{1}$ and $\mathbf{R} 3$ at $1.2 \times 10^{-4} \mathrm{M}$ in dichloromethane according to the method of continuous variations and resultant Job plot (D) of $\Delta$ Abs at $560 \mathrm{~nm}$.

Table 1. Diffusion constants and calculated hydrodynamic radius determined from DOSY experiments. ${ }^{[a]}$

\begin{tabular}{llll}
\hline Species & $D\left(10^{-9} \mathrm{~m}^{2} / \mathrm{s}\right)$ & $R(\mathrm{~nm}) I^{[\mathrm{b}]}$ & $V\left(\mathrm{~nm}^{3}\right)^{[\mathrm{c}]}$ \\
\hline $\mathbf{1}$ & 1.5 & 3.1 & 15.1 \\
$\mathbf{1 \cdot R 2}$ & 2.4 & 1.0 & 3.5 \\
$\mathbf{1 \cdot R 3}$ & 2.1 & 1.2 & 5.0 \\
\hline
\end{tabular}

[a] In dichloromethane solution at $0.5 \mathrm{mM}$. [b] Hydrodynamic radius calculated from the Einstein-Smoluchowsky equation. [c] Hydrodynamic volume.

The formation of the $2 \times 2$ and $2 \times 3$ ladder complexes $1 \cdot \mathbf{R 2}$ and $\mathbf{1} \cdot \mathbf{R} 3$ is expected to influence the redox properties of the electroactive triphenylenevinylene moiety. ${ }^{[47,48]}$ The latter readily undergoes reversible oxidation to form the corresponding radical cation. To probe the redox properties of 1 when it is in the environment afforded by the complexes $\mathbf{1} \cdot \mathbf{R} \mathbf{2}$ and $\mathbf{1} \cdot \mathbf{R} \mathbf{3}$, cyclic voltammetry was used to determine the oxidation potentials of the complexes. Dichloromethane was used as the solvent to ensure favorable formation of the complexes under the experimental conditions. However, because 1 alone undergoes 
aggregation in dichloromethane, an excess of $\mathbf{R} \mathbf{1}$ was added to form the $\mathbf{1 \cdot R} \mathbf{1}$ complex. Control experiments with R1, R2, and R3 showed that they do not possess redox activity under the conditions employed for the experiments. As expected, 1・R1 possesses a single redox wave corresponding to the formation of the monomer radical cation (Table 2). This contrasts the behavior of $\mathbf{1 \cdot R 2}$ which instead possesses two redox waves, the first one occurs at a potential that is higher than the one for $\mathbf{1} \cdot \mathbf{R} \mathbf{1}$ and is followed by a second wave leading to the formation of the radical dication. We attribute the difference in the oxidation potentials between $\mathbf{1} \cdot \mathbf{R} \mathbf{1}$ and $\mathbf{1 \cdot R} \mathbf{2}$ for formation of the radical cation $\left(\Delta E_{\text {ox }}=65 \mathrm{mV}\right)$ to the steric constraints imposed on 1 upon formation of $\mathbf{1 \cdot R 2}{ }^{[49]}$ In the case of $\mathbf{1 \cdot R} \mathbf{3}$, one may expect three oxidation steps, one for each of the triphenylenevinylene units in the complex. Experimentally, only two one electron oxidation events are observed instead. Their separation is smaller than that in $\mathbf{1 \cdot R 2}(110$ vs. $150 \mathrm{mV}$ for $\mathbf{1} \cdot \mathbf{R} \mathbf{2}$ and $\mathbf{1} \cdot \mathbf{R} \mathbf{3}$, respectively). A reasonable explanation is that the formation of the radical trication $(\mathbf{1} \cdot \mathbf{R} \mathbf{3})^{3+}$ lies beyond the experimentally accessible solvent window. Another possibility is that the $\mathbf{1} \cdot \mathbf{R} 3$ complex only binds two molecules of 1 , but this would be in disagreement with the spectral changes observed upon formation of $\mathbf{1 \cdot R} \mathbf{3}$. Indeed, for $\mathbf{1} \cdot \mathbf{R} \mathbf{3}$ to possess a smaller separation between the oxidation potentials than $\mathbf{1} \cdot \mathbf{R} \mathbf{2}$ implies that only the two distal binding sites in $\mathbf{R} \mathbf{3}$ are occupied. If this were the case, the interchromophore spacing would be increased to $>10 \AA$, resulting in an environment expected to be more similar to that of $\mathbf{R} \mathbf{1}$ than of $\mathbf{R} \mathbf{2}$.

Table 2. First and second electrochemical potentials for oxidation of 1 in the complexes. $^{\text {[a] }}$

\begin{tabular}{lllll}
\hline Species & $E_{\text {ox }}^{\prime}(\mathrm{V})$ & $E_{\text {ox }}^{\prime \prime}(\mathrm{V})$ & $\Delta V(\mathrm{mV})^{\mathrm{l}}$ & $K_{c}$ \\
\hline $\mathbf{1} \cdot \mathbf{R} \mathbf{1}$ & 0.575 & - & - & - \\
$\mathbf{1 \cdot R 2}$ & 0.640 & 0.790 & 150 & 340 \\
$\mathbf{1 \cdot R 3}$ & 0.635 & 0.745 & 110 & 70 \\
\hline
\end{tabular}

[a] In dichloromethane solution with respect to ferrocene used as an internal standard.

The difference in potential between the oxidation of the first and second molecules of $\mathbf{1}$ in the $\mathbf{1 \cdot R 2}$ and $\mathbf{1 \cdot R} \mathbf{3}$ complexes provides information on the relative stabilization of the radical dications. If no interactions were present, then all the electroactive units in the complexes would undergo single electron oxidation at the same potential. The interaction afforded by the assembly can be evaluated from the comproportionation constant $\left(K_{\mathrm{c}}\right)$ according to: ${ }^{[50]}$

$$
K_{c}=e^{\left(\frac{F}{R T}\right) \Delta E_{o x}}
$$

where $F$ is the Faraday constant and $\Delta E_{\text {ox }}$ is the difference in oxidation potential in Volts. As can be seen from Table 2, both $\mathbf{1} \cdot \mathbf{R} \mathbf{2}$ and $\mathbf{1} \cdot \mathbf{R} \mathbf{3}$ possess $K_{\mathrm{c}}>1$, indicating interactions between the two charges located on the same complex. The value is lower for $\mathbf{1 \cdot R 3}$ as expected for a greater delocalization of the positive charges over the three electroactive units in the complex.

Interactions between intermolecular orbitals can be understood using the Hückel approximation by following the magnitude of the transfer integral $t .^{[51]}$ As the number of repeating units increases, the separation between discrete energy levels decreases and the bandwidth approaches the value of an infinite chain (Figure 4). In the comparison between the splitting induced by the formation of the $\mathbf{1} \cdot \mathbf{R} \mathbf{2}$ vs. $\mathbf{1} \cdot \mathbf{R} \mathbf{3}$ complexes, we note that the ratio of the observed splitting in $E_{\mathrm{ox}}$ is $150 / 110=1.35$. In the energy diagram, this corresponds to the ratio between the difference in energy levels of the dimer and trimer, which is given by $2 t /(\sqrt{ } 2) t=1.41$. The two values are in reasonably good agreement, suggesting that the supramolecular assemblies may be adequate models for exploring the electronic interactions in extended m-staked assemblies.

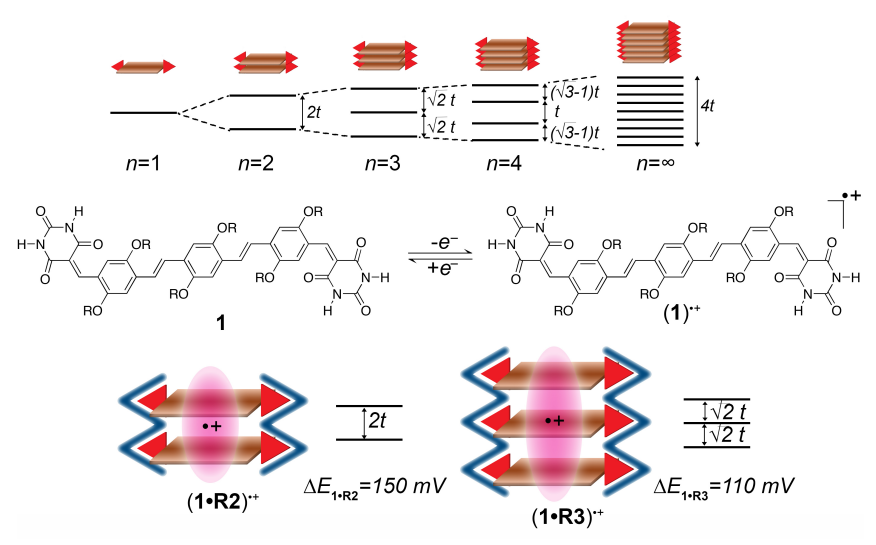

Figure 4. Stacking of $\pi$-conjugated chromophores induces electronic interactions that, according to the Hückel approximation, split the energy levels by multiples of the transfer integral $t$. In the case of 1 , a single oxidation event corresponding to the formation of the radical cation is observed. Two oxidation steps are instead observed for both the $\mathbf{1 \cdot R 2}$ and $\mathbf{1 \cdot R} \mathbf{3}$ complexes. The experimentally observed ratio of the difference in the redox potential between each oxidation step, $\Delta E$, is close to the expected value of $\sqrt{2}$ predicted by Hückel theory.

\section{Conclusion}

Just as the oligomer model has greatly contributed to the understanding of the intramolecular properties of electroactive polymers, the use of well-defined supramolecular architectures can allow insights to the intermolecular interactions between adjacent electroactive units. A key feature of supramolecular self-assembly is that different $3 \mathrm{D}$ architectures may be prepared from common subunits, thereby facilitating synthetic accessibility to a variety of topologies. Here, the use of $\mathrm{H}$-bonding interactions for the formation of $n \times m$ ladders incorporating 2 or 3 triphenylenevinylene units in a co-planar orientation was explored, but other geometries may be accessible using different receptors. The proximity enforced by the complex leads to interesting electronic effects as manifested in the absorption, emission, and redox properties. In particular, it was observed that the stabilization afforded by the delocalization of the radical cation increases in the order $m=2<m=3$ as expected for the delocalization of holes in stacked conjugated molecules. On the other hand, we also note the increase in complexity for the unambiguous characterization of higher-order supramolecular assemblies. Although the combination of spectral and redox information collected for the $\mathbf{1 \cdot R 2}$ and $\mathbf{1 \cdot R} \mathbf{3}$ complexes examined herein are in agreement with the proposed structures, the unequivocal characterization of larger assemblies may be 
more difficult. Although the phenylene spacer in $\mathbf{R} \mathbf{2}$ and $\mathbf{R} 3$ is near-optimal in terms of rigidity and geometric constraints, some distortion is nonetheless likely upon formation of the $\mathrm{H}$-bonded assemblies as judged from the solid-state structure of the parent system. ${ }^{[52]}$ This could be amplified in the larger assemblies, eventually leading to frustration of the $\mathrm{H}$-bonding sites. In the light of this, careful design of the supramolecular self-assembled structures can be used to favor formation of desired topologies.

\section{Experimental Section}

The compounds used were prepared according to the protocols described in the supplementary information. Spectroscopic grade solvents were used for the binding studies. UV-Vis and emission spectra were collected on a Varian Cary 5 spectrophotometer and Horiba Fluoromax fluorimeter, respectively. DOSY NMR experiments were performed at $298 \mathrm{~K}$ on a Bruker DPX 400 equipped with a $5 \mathrm{~mm}$ gradient inverse broadband probe. Diffusion measurements were performed at a concentration of $0.5 \mathrm{mM}$ for 1 with a stoichiometric amount of receptor using a ${ }^{1} \mathrm{H}$ NMR pulsed-gradient experiment. The stimulated spin-echo sequence ${ }^{51}$ which leads to the measurement of the translational selfdiffusion coefficients $D$, where $D$ is the slope of the straight line obtained when $\ln (I)$ is plotted against the square of the gradient-pulse power according to the following equation: $\ln (I)=-\gamma^{2} g^{2} D \delta^{2}(\Delta-\delta / 3)$, where $I$ is the relative intensity of a chosen resonance, where $Y$ is the proton gyromagnetic ratio, $\Delta$ the intergradient delay $(150 \mathrm{~ms}), \delta$ the gradient pulse duration $(1,3 \mathrm{~ms})$, and $G$ the gradient intensity (10 values varying from 0.01 to $0.40 \mathrm{G} / \mathrm{m}$ were used). The diffusion constant of dichloromethane $\left(3.82 \times 10^{-9} \mathrm{~m}^{2} / \mathrm{s}\right)^{[53]}$ was used to calibrate the measurements. Electrochemical studies were performed on a BAS100B Electrochemical Analyzer. (Bioanalytical Systems, Inc.) Cyclic voltammograms were recorded in dichloromethane with $0.1 \mathrm{M}$ tetrabutylammonium hexafluorophosphate $\left(\mathrm{TBAPF}_{6}\right)$ as the supporting electrolyte. The working electrode was a graphite disc, the counter electrode was a platinum wire, and an Ag wire in $0.1 \mathrm{M} \mathrm{TBAPF}_{6}$ solution was used as a pseudo reference electrode. The reported oxidation potentials were obtained with a scan rate of $20 \mathrm{mV} \cdot \mathrm{s}^{-1}$ and are reported with respect to ferrocene added as an internal reference. Molecular modelling was performed using the MM5 molecular mechanics force field in the Hyperchem program.

\section{Acknowledgements}

We are grateful to Prof. Miklos Kertesz for helpful discussions on the stabilization of organic radicals and to Mr. Sven Rotering for help in the synthesis of 1 . The assistance of the CESAMO platform for characterization of organic molecules is gratefully acknowledged.

Keywords: Supramolecular Chemistry • Molecular Recognition • Redox Chemistry $•$ Stacking Interactions $\bullet$ Hydrogen-bonding

[1] F. Wurthner, Z. J. Chen, F. J. M. Hoeben, P. Osswald, C. C. You, P. Jonkheijm, J. von Herrikhuyzen, A. Schenning, P. van der Schoot, E. W. Meijer, E. H. A. Beckers, S. C. J. Meskers, R. A. J. Janssen J. Am. Chem. Soc. 2004, 126, 10611-10618.

[2] F. J. M. Hoeben, J. Zhang, C. C. Lee, M. J. Pouderoijen, M. Wolffs, F. Wurthner, A. Schenning, E. W. Meijer, S. De Feyter Chem. Eur. J. 2008, 14, 8579-8589.

[3] A. Wadsworth, Z. Hamid, J. Kosco, N. Gasparini, I. McCulloch Adv. Mater. 2020, 32, 2001763.
[4] S. J. Lou, S. Loser, K. A. Luck, N. Zhou, M. J. Leonardi, A. Timalsina, E. F. Manley, D. Hayes, J. Strzalka, M. C. Hersam, R. P. H. Chang, T. J. Marks, L. X. Chen J. Mat. Chem.C. 2020.

[5] C. Grand, S. Baek, T.-H. Lai, N. Deb, W. Zajaczkowski, R. Stalder, K. Müllen, W. Pisula, D. G. Bucknall, F. So, J. R. Reynolds Macromolecules. 2016, 49, 4008-4022.

[6] L. Biniek, N. Leclerc, T. Heiser, R. Bechara, M. Brinkmann Macromolecules. 2013, 46, 4014-4023.

[7] P. H. Lambrev, P. Akhtar, H.-S. Tan Biochim. Biophys. Acta, Bioenerg. 2020, 1861, 148050.

[8] M. d. Rey, A. W. Chin, S. F. Huelga, M. B. Plenio J. Phys. Chem. Lett. 2013, 4, 903-907.

[9] R. Hildner, D. Brinks, J. B. Nieder, R. J. Cogdell, N. F. van Hulst Science. 2013, 340, 1448-1451.

[10] Y.-C. Cheng, G. R. Fleming Annu. Rev. Phys. Chem. 2009, 60, 241262.

[11] T. F. A. De Greef, M. M. J. Smulders, M. Wolffs, A. P. H. J. Schenning, R. P. Sijbesma, E. W. Meijer Chem. Rev. 2009, 109, 5687-5754.

[12] F. J. M. Hoeben, P. Jonkheijm, E. W. Meijer, A. P. H. J. Schenning Chem. Rev. 2005, 105, 1491-1546.

[13] C.-C. Chu, G. Raffy, D. Ray, A. D. Guerzo, B. Kauffmann, G. Wantz, L. Hirsch, D. M. Bassani J. Am. Chem. Soc. 2010, 132, 12717-12723.

[14] D. M. Bassani, L. Jonusauskaite, A. Lavie-Cambot, N. D. McClenaghan, J. L. Pozzo, D. Ray, G. Vives Coord. Chem. Rev. 2010, 254, 24292445.

[15] K. T. Wong, D. M. Bassani NPG Asia Materials. 2014, 6.

[16] P. Prins, K. Senthilkumar, F. C. Grozema, P. Jonkheijm, A. Schenning, E. W. Meijer, L. D. A. Siebbeles J. Phys. Chem. B. 2005, 109, 1826718274.

[17] M. Sandroni, A. Maufroy, M. Rebarz, Y. Pellegrin, E. Blart, C. Ruckebusch, O. Poizat, M. Sliwa, F. Odobel J. Phys. Chem. C. 2014, 118, 28388-28400.

[18] V. K. Praveen, C. Ranjith, E. Bandini, A. Ajayaghosh, N. Armaroli Chem. Soc. Rev. 2014, 43, 4222-4242.

[19] O. Dumele, J. Chen, J. V. Passarelli, S. I. Stupp Adv. Mater. 2020, 32, 1907247.

[20] A. Jain, S. J. George Mater. Today. 2015, 18, 206-214.

[21] S. Mahesh, R. Thirumalai, S. Yagai, A. Kitamura, A. Ajayaghosh Chem Commun. 2009, 5984-5986.

[22] F. J. M. Hoeben, J. Zhang, C. C. Lee, M. J. Pouderoijen, M. Wolffs, F. Wurthner, A. Schenning, E. W. Meijer, S. De Feyter Chem. - Eur. J. 2008, 14, 8579-8589.

[23] A. Ajayaghosh, V. K. Praveen Acc. Chem. Res. 2007, 40, 644-656.

[24] A. Ajayaghosh, V. K. Praveen, C. Vijayakumar Chem. Soc. Rev. 2008, 37, 109-122.

[25] Z. J. Chen, A. Lohr, C. R. Saha-Moller, F. Wurthner Chem. Soc. Rev. 2009, 38, 564-584.

[26] K. K. Kartha, V. K. Praveen, S. S. Babu, S. Cherumukkil, A. Ajayaghosh Chem. Asian J. 2015, 10, 2250-2256.

[27] H. Miyajima, M. C. Z. Kasuya, A. Del Guerzo, J.-M. Vincent, K. Hatanaka J. Fluorine Chem. 2018, 205, 30-34.

[28] A. Chakrabarty, M. Maity, G. Raffy, S. Marre, C. Aymonier, U. Maitra, A. Del Guerzo ChemNanoMat. 2020, 6, 79-88.

[29] A. Mishra, P. Baeuerle Angew. Chem., Int. Ed. 2012, 51, 2020-2067.

[30] A. Mishra, C.-Q. Ma, P. Baeuerle Chem. Rev. 2009, 109, 1141-1276.

[31] J.-M. Lehn, Supramolecular Chemistry: Concepts and Perspectives, Wiley-VCH, Weinheim, 1995

[32] Y. F. Chen, G. V. Dubacheva, K. P. Tseng, G. Raffy, A. D. Guerzo, L. Hirsch, J. J. Shyue, K. T. Wong, D. M. Bassani Pure Appl. Chem. 2014, 86, 471-481.

[33] Y. Yao, W. Shen, B. Nohra, C. Lescop, R. Réau Chem. - Eur. J. 2010, 16, 7143-7163.

[34] B. Nohra, S. Graule, C. Lescop, R. Réau J. Am. Chem. Soc. 2006, 128, 3520-3521.

[35] H. Nierengarten, E. Leize, E. Breuning, A. Garcia, F. Romero-Salguero, J. Rojo, J.-M. Lehn, A. Van Dorsselaer J. Mass Spectrom. 2002, 37, 56-62.

[36] E. Breuning, U. Ziener, J.-M. Lehn, E. Wegelius, K. Rissanen Eur. J. Inorg. Chem. 2001, 1515-1521. 
[37] U. Ziener, E. Breuning, J.-M. Lehn, E. Wegelius, K. Rissanen, G. Baum, D. Fenske, G. Vaughan Chem. - Eur. J. 2000, 6, 4132-4139.

[38] A. M. Garcia, F. J. Romero-Salguero, D. M. Bassani, J.-M. Lehn, G. Baum, D. Fenske Chem. - Eur. J. 1999, 5, 1803-1808.

[39] L. R. Macgillivray, G. S. Papaefstathiou, T. Friščić, T. D. Hamilton, D. K. Bučar, Q. Chu, D. B. Varshney, I. G. Georgiev Acc. Chem. Res. 2008, 41, 280-291.

[40] S. K. Chang, A. D. Hamilton J. Am. Chem. Soc. 1988, 110, 1318-1319.

[41] K. T. Mahmudov, M. N. Kopylovich, A. M. Maharramov, M. M. Kurbanova, A. V. Gurbanov, A. J. L. Pombeiro Coord. Chem. Rev. 2014, 265, 1-37.

[42] N. D. McClenaghan, Z. Grote, K. Darriet, M. Zimine, R. M. Williams, L. De Cola, D. M. Bassani Org. Lett. 2005, 7, 807-810.

[43] A. M. Ramos, M. T. Rispens, J. K. J. van Duren, J. C. Hummelen, R. A. J. Janssen J. Am. Chem. Soc. 2001, 123, 6714-6715.

[44] C. Mongin, A. M. Ardoy, R. Méreau, D. M. Bassani, B. Bibal Chem. Sci. 2020, 11, 1478-1484.

[45] W. C. Vosburgh, G. R. Cooper J. Am. Chem. Soc. 1941, 63, 437-442.

[46] Y. Cohen, L. Avram, L. Frish Angew. Chem. Int. Ed. 2005, 44, 520-554.

[47] M. Kertesz Chem. - Eur. J. 2019, 25, 400-416.

[48] J. Seixas de Melo, J. Pina, H. D. Burrows, R. E. Di Paolo, A. L. Macanita Chem. Phys. 2006, 330, 449-456.

[49] Molecular modeling indicates that formation of the ladder assemblies is accompanied by a twist of the $\mathrm{C}-\mathrm{C}$ single bond between the terminal phenyl and the barbiturate group. This would reduce the contribution of the barbiturric acid moieties to the stabilization of the radical cation.

[50] S. Ernst, V. Kasack, W. Kaim Inorg. Chem. 1988, 27, 1146-1148.

[51] Y. Kashimoto, K. Yonezawa, M. Meissner, M. Gruenewald, T. Ueba, S. Kera, R. Forker, T. Fritz, H. Yoshida J. Phys. Chem. C. 2018, 122, 12090-12097.

[52] S. K. Chang, D. Van Engen, E. Fan, A. D. Hamilton J. Am. Chem. Soc. 1991, 113, 7640-7645.

[53] H. Kato, T. Saito, M. Nabeshima, K. Shimada, S. Kinugasa J. Mag. Res. 2006, 180, 266-273. 


\section{Entry for the Table of Contents}

Graphic for Table of Contents:

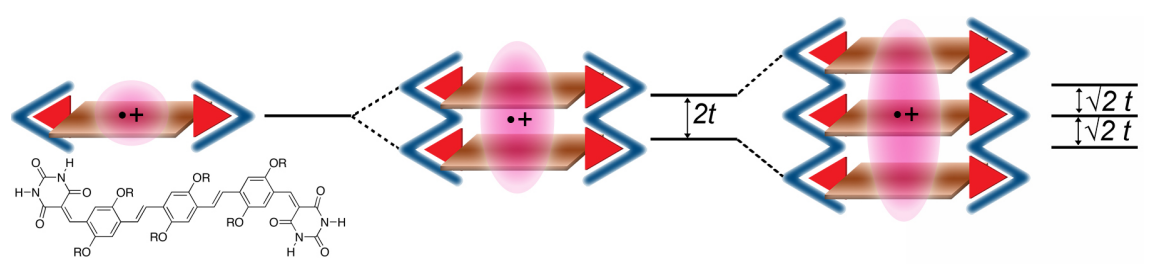

Supramolecular self-assembly directs the stacking of terphenylenevinylene units to mimic hole delocalization in materials for organic electronics. 